\title{
Lighting and Museum Exhibits
}

\author{
Malcolm Innes
}

\begin{abstract}
Museums exist to display and preserve valuable artefacts. Display lighting helps fulfil one of the main tenets of a museum, but excessive light causes irreparable damage to sensitive exhibits. Getting the balance between good display lighting and good conservation conditions is often difficult, but not impossible. Good exhibit lighting is not accidental. A considered process of design ideation and refinement is required to render exhibits to best effect. This thoughtful process is not explicit in the installation; nevertheless, by analysing methodologies that an experienced designer may consider as 'intuitive', the author establishes the critical design practices that underpin effective lighting for museum exhibits. The author explores factors that may impair viewing conditions and how the human physiological response to light can work against us in dimly lit galleries. However, considered use of light can reveal details of texture, shape, and decoration that could easily be missed in low light conditions.
\end{abstract}

\section{Keywords}

conservation lighting, virtual restoration, digital projection, shadow, texture, depth, colour rendering, colour temperature, glare, reflections, disability glare, phototropism, raking light 


\section{Introduction}

When an archaeological artefact stops being described as a find and becomes an exhibit in a museum collection, it marks an important transition in how people interact with it. A new find on a dig is likely to be extensively handled and examined in great detail by a whole series of specialists. The act of holding an object, feeling its weight, its texture, and its thermal conductivity, provides us with an immense amount of sensory information about the object. This haptic interaction can often explain a truth about the object that is not visibly discernible. This physical contact is a vital but possibly underestimated tool that helps to unlock some of the finds' properties.

Once on display in the museum, physical contact with the object is in most cases lost. Museum displays are almost exclusively non-contact areas. The act of handling an object may have helped reveal to the archaeologist crucial information about the story of the object (Cain 2005; Spark 2010), but the continued touch and handling by hundreds or thousands of museum visitors is a major threat to the continued survival of the object. The risk of physical damage, theft, or chemical contamination (Thomson 1986) through continued handling means that our trips to museums as visitors will inevitably not be a very tactile experience, thus denying the active tactual participation that people prefer (Dean 1994; Pye 2008).

Our isolation from museum exhibits goes further than just the exclusion of touch. Of all our sensory modalities, i.e. sight, smell, hearing, taste, and touch, it is sight that often provides the only sensory connection between the visitor and the museum artefact. Although many early museums allowed visitors to interact directly with exhibits (Classen 2007), this level of access is now exceptionally rare due to stricter conservation practices (Finney 2006).

In the absence of other sensory stimuli, our visual experience of museum displays becomes paramount. This might suggest that we must maximize illumination levels to provide the best possible visual experience to the visitor. However, for conservation reasons (Thomson 1963), this is often not an option. Nevertheless, as this chapter indicates there are both simple lighting techniques and digital technologies that can 
significantly improve the visual experience for museum visitors. Furthermore, some common museum lighting problems are highlighted, including low lighting levels, reflections, and glare, along with methodologies to avoid these difficulties. Beginning with an exploration of the reasons behind the restricted light levels used in museum environments, we will discuss the accurate rendering of objects' colours, the use of light as an interpretive medium, how lighting quality can be measured, and the possibilities of using light to virtually restore exhibits.

\section{The dichotomy at the heart of the museum}

Museums have a dual role: they exist both to preserve and to display the artefacts that make up their collections. They exist to conserve objects of cultural and historical significance and display those objects to the public for the purposes of education. These two roles are not always mutually compatible. Garry Thomson (1986) in his seminal book The Museum Environment, detailed some of the environmental factors that can act on sensitive materials in museum exhibits and alter, weaken, and ultimately destroy precious museum collections over time. Light was one of the potential damaging influences discussed by Thomson (see Kotoula this volume).

Conservation practice in museums is partly restorative, but it is mostly preventive, defining storage and display conditions that will minimize potential damage to artefacts (Museums Galleries Scotland 2014). Alongside recommendations on dealing with chemical, biological, thermal, and mechanical threats to museum collections, modern conservation practice has a lot to say about light and the damage that it can cause (Trylski 2015; National Library of Australia 2014). One of the best summaries of light-related issues in museums is published by the Commission Internationale de l'Éclairage (CIE 2004), a technical and scientific organization dedicated to sharing knowledge about the science and art of light, colour vision, photobiology, and image technology.

In the museum environment, light is both a hero and a villain. It is the hero that enables sight, the only sense that we are normally allowed to use to interact with museum exhibits, while at the same time a villain, because the very light that enhances the visual 
appearance of the exhibit can be responsible for its destruction. For instance, exposure to light can cause fading of fugitive pigments and the breakdown of organic materials (Saunders and Kirby 1994). This light-induced fading has been known for millennia; as Forbes (1971) describes in Studies in Ancient Technology, a principal use of dyes in Ancient Rome was to redye clothing faded by exposure to sunlight. It is therefore understandable that control of light is a vital aspect of the storage and display of museum exhibits where we are trying to conserve collections for future generations.

In the 1950s and 1960s, work to quantify and limit the damaging effects of visible and ultraviolet light led to the publication of a series of recommendations (Thomson 1957; 1963). Thomson's research exploring the effect of light in the museum was consolidated into a section of his 1978 book The Museum Environment, a text that became the de facto reference for museum professionals. An updated and extended second edition was published eight years later (Thomson 1986). The lighting recommendations created by Thomson became common practice with museums and galleries around the world, and the influence of his work continues to the present day, as it has been formalized in international standards for museum and gallery lighting (CIE 2004).

But what is the problem with light in the museum, and why do light levels have to be restricted? Fundamentally, light is energy. As described by the nineteenth-century scientist James Clerk Maxwell (1865), visible light is part of the electromagnetic spectrum of energy that spans from radio waves to $\mathrm{x}$-rays and gamma rays. Whilst we experience some parts of the electromagnetic spectrum as heat (infrared radiation), we cannot directly sense most of the spectrum. However, within the human visual system we have specially adapted nerve cells that are sensitive to parts of the electromagnetic spectrum. Electromagnetic energy with wavelengths between approximately 380 and 760 nanometres triggers a chemical response in the retina of our eyes that is interpreted and processed by our brains to deliver the sense of sight (Mueller and Rudolph 1970).

Objects and materials exposed to electromagnetic energy selectively absorb or reflect the radiation (Thomson 1986: 6). Absorption of light radiation can lead to heating 
of the material (especially true in the infrared part of the spectrum), or to a photochemical reaction leading to a permanent chemical change in the molecular structure of the object. The most common visible results of photochemical damage are the fading of colours and an increasing brittleness of materials (Cuttle 2008). Higher energy levels of radiation are likely to be more readily absorbed by organic materials, and this will exacerbate the amount of photochemical damage produced (CIE 2004). As Thomson said, 'deterioration needs energy - either light or heat. Light is much more potent than heat in the museum' (Thomson 1986: 4). Within visible light, the blue end of the spectrum provides more radiant energy than the red end of the spectrum and can therefore impart more damage (Cuttle 2013: 277, 42). Ultraviolet radiation, which sits beyond the blue end of the spectrum, represents significantly higher energy levels than blue light (Thomson 1986: 15). However, it does not contribute to human vision, since our visual system is not sensitive to these wavelengths of electromagnetic energy. Therefore, the minimization or exclusion of ultraviolet radiation is a fundamental requirement of conservation lighting (Thomson 1957). It is for this reason that unfiltered natural light, which tends to be relatively high in ultraviolet radiation, is very rarely a feature of galleries where sensitive exhibits are on display.

The damaging effect of light energy is cumulative; it is the total quantity of energy over a period of time that defines how much damage may be caused to the exhibit. As Thomson noted, because of this cumulative effect, the net effect of an object illuminated at a low light level for 100 days, or an object illuminated at 100 times the light level for one day, would be the same (Thomson 1986: 21). The maximum light levels defined for conservation lighting are based on the knowledge of annual opening hours for museums, and are usually defined as being the highest level of visible light that will produce a 'just noticeable fade' of a coloured 'blue-wool standard' over 50 years (National Library of Australia 2014; also see Cuttle 2013: 47). In most cases however, there is no universal standards for museum and gallery lighting and institutions often create their own lighting guidelines for different kind of materials. 
Different materials absorb and reflect visible light in different ways, with some materials being relatively unaffected by high levels and others being damaged very quickly. The best available guidance for conservation lighting will take this variability into account and categorize materials according to their sensitivity to light (CIE 2004). Whether guidelines come from the institution itself or are based on technical documents such as the CIE's Control of Damage to Museum Objects by Optical Radiation (CIE 2004), the aim is to secure the visible character of the exhibits for future generations. A material that has received ten 'Just Noticeable Fades' is usually considered too faded to be on display; therefore conservation lighting would be expected to degrade a coloured material gradually enough to ensure that it was suitable to display for about 500 years (National Library of Australia 2014).

Although not all materials are equally affected by excessive light, restricted light levels are the norm in museum environments in order to reduce excessive contrast between areas of highly light-sensitive and less light-reactive exhibits. Very low-light levels in museums denote the presence of very sensitive materials within the exhibits. Unglazed pigments and colourings, coloured feathers, fur, leather, and plant material, along with many other organic materials, are amongst the most light-reactive materials in museum collections (CIE 2004).

Whilst the continued preservation of sensitive materials is aided by reducing visible light levels, this does little to improve the visual experience for the visitor. Within reasonable limits, visual acuity improves proportionally with higher light levels (Gregory 1997: 92; Boyce and Raynham 2009: 26). With objects in our own control, it is natural to switch on a desk lamp or take the object to a day-lit window to increase the illumination so that we can see more detail. In museum environments this is not possible, and some of the smallest and most detailed exhibits are often among the most dimly illuminated. Nevertheless, by careful manipulation of exhibition lighting, a lighting designer is able to use techniques such as adding balanced amounts of ambient lighting (Cuttle 2013: 213; also see Thomson 1986: 27 for examples of how ambient lighting can enhance a sense of brightness and improve visual acuity) and developing a clear hierarchy of illumination 
levels (Innes 2012: 74) to maximize the amount of visual information that is delivered to the viewer.

\section{Light and colour}

As visitors to museums and heritage sites, we are conditioned to have a very monochromatic view of the past (see Leibhammer this volume). Photographic history is dominated by stark and arresting black and white images, but our sepia-tinted view of the past is about much more than just historical photographs - it extends into our expectations of a history devoid of colour. We visit the ruins of castles, cathedrals, or peasant dwellings and often gaze upon a world of stone. We marvel at the intricate expertise of the master craftsmen who created such three-dimensional forms, skilfully hewn from solid stone. To most visitors, the ancient world appears to have been beautifully carved, but essentially monochrome. As Professor Mark Edmonds of the Ness of Brodgar excavations in Orkney, UK, has argued, 'we see Neolithic remains after they have been bleached out and eroded. However, it is now clear from Brodgar that buildings could have been perfectly cheerful and colourful' (McKie 2012). We have so few extant examples of colour in everyday historic environments, it can often seem to visitors that, beyond distinct artworks, decorative colour was some kind of invention of the postindustrial age.

Although the polychromatic environment that our ancestors created is well known to scholars, it is difficult to look at the remains of objects and structures and be able to fully appreciate the vibrancy of the ancient world (Bomford 1995). Either in managed historic sites or in museums, visitors are often presented with an artist's illustration of the object or site as it may have originally looked. However, it is often difficult to reconcile the artist's impression with the denuded objects in front of us.

The decorative finishes that our ancestors carefully crafted to add visual interest to their built environment are often the first layer of evidence to disappear. The fugitive nature of many natural pigments means that their longevity is limited. Pigments can be destroyed by different environmental factors, while decomposition does not stop when 
objects are moved to museums (Thomson 1963). Whilst repainting is not possible for museum artefacts, it is still important to give the museum visitor an understanding of what these objects would have looked like in the past. Light can be used to perform this function.

Where some traces of original colour remain on an object, it is possible to enhance the appreciation of that colour with careful application of exhibit lighting. It should be remembered that the colours we see in objects and materials around us, are simply a function of light (see Pettitt this volume). The sensation of colour is how our visual system responds to visible light stimuli of different wavelengths (Zelanski and Fisher 1999). Blue is a visual response to electromagnetic radiation around 450-480 nanometres, red is a visual response to light between 620 and 750 nanometres. For example, a red mosaic tile appears so because its surface reflects red light more strongly than other wavelengths of light (Cuttle 2013: 31). However, to reflect red light, the tile needs to be illuminated with light that includes wavelengths from the red part of the spectrum. If the same tile is illuminated with only blue light, the surface will not reflect red and therefore it will appear dark (Innes 2012: 21). For museum exhibits it is therefore essential to provide high-quality light sources that provide a complete spectrum of all wavelengths of visible light; this usually means a really good-quality white light source, without unnatural peaks or troughs in any part of the visible spectrum (Innes 2013).

\section{The importance of light as interpreter in the museum}

As vision is often our only sensory connection with museum exhibits, light has to intercede between the object and viewer, to act as interpreter and reveal as much as possible about the nature of the object. High-quality white light will allow the true colours of an object to be seen, but that is not the only contribution of light. Shadow can be used as a deliberate tool to model the three-dimensional form of the object and reveal the surface texture. In certain circumstances, shadow can also become an active part of the display (Cuttle 2013: 163). 
Museums are alien places for the exhibits on display, but an important consideration for the lighting designer is to understand what the object may have looked like in its original setting. The task is then to consider whether representing the original setting enhances the interpretation of the object. If so, can display lighting be used creatively to recreate some sense of that original setting, whether that is a clear shaft of summer sunlight or the flickering light of a hearth?

A key exhibit in St Mungo's Museum of Religious Life and Art, Glasgow, Scotland, is a large bronze statue of the Hindu god Shiva (Shaw 2000). The multiplelimbed figure captures a frozen moment in a cosmic dance. The positioning of the exhibit makes a minimalist reference to the original temple setting, where the statue would be placed in front of an undecorated wall. In the temple, oil lamps with multiple wicks would dimly illuminate the statue. The guttering and flickering light from these multiple light sources appeared to make the statue come alive by creating a multitude of trembling shadows on the temple walls. The lighting design was carried out by the author and Kevan Shaw of KSLD, and it involved the creation of two custom-designed devices that used rotating textured glass lenses, moving in front of twin lamps to replicate the effect of flickering light from multiple lantern flames. As a result, animated shadows give to the static exhibit the added dimensions of time and movement to help the viewers appreciate the object the way it was intended to be seen.

Whilst the dancing of the Shiva statue was created with real motion in the lighting rather than relying on movement of the object or observer, apparent movement can easily be created by dimming multiple light sources shining from different directions, thereby fading between long and short shadows to give a sense of motion. In a similar fashion, changes in the angle of illumination, the intensity, or the colour of the light can be used to reference the diurnal patterns of daylight and impart a strong sense of time to a static exhibit.

\section{Light to reveal or conceal: texture, shadow and form}


Whilst visual acuity (the ability of the visual system to resolve fine detail) is directly proportional to the quantity of available illumination (Gregory 1997: 92; Boyce and Raynham 2009: 26), photochemical damage to exhibits is irreparable (Thomson 1986; CIE 2004; Trylski 2015: 24). Therefore, how can sensitive exhibits be effectively illuminated without destroying them? To protect sensitive museum exhibits and slow any photochemical damage, display lighting levels are restricted. However, in such conditions, simply illuminating all parts of the exhibit with the maximum allowable amount of light does not improve visibility: in fact, it may significantly degrade the visual acuity by reducing contrast (Cuttle 2013: 37). In these conditions, sometimes less light can lead to more understanding.

Our understanding of material properties is based on many aspects of the object studied. The way the surface selectively reflects or absorbs different wavelengths of light gives us the sensation of the object's colour; similarly, the way that surfaces reflect, refract, diffuse, transmit, or absorb light give us an understanding of how shiny, glassy, matt, translucent, or opaque the object is (Cuttle 2013: 34). All these descriptive attributes are best served by relatively bright light sources; however, some physical attributes, such as the texture and form of an object, are best revealed with the controlled use of darkness.

Shadow is a very important visual cue to the three-dimensional shape of an object (Casati 2004), and can be invaluable in revealing the textural quality of surfaces that we cannot physically touch (Thomson 1986: 27). Subconsciously, our visual system relies heavily on shadow patterns to aid the interpretation of three-dimensional forms (Gregory 1997: 189). Our perception is heavily based on our past visual experiences of how light and shade interact with physical surfaces and materials and the normal directions of natural light that may cast those shadows (because natural light predominantly comes from overhead, there is a tendency to interpret any shading on an object as being the result of a light source from above (Kleffner and Ramachandran 1992). Lidwell et al. (2010: 240) note that 'this bias is found across all age ranges and cultures, and likely results from humans evolving in an environment lit from above by the Sun.' Shadows also provide subtle depth cues that can allow us to infer the positioning of objects or parts 
of objects even when they are too far away for our stereo vision to work effectively (Innes 2012: 19). This knowledge of shadows can help a designer plan better lighting for museum exhibits.

The small island of Iona sits off the west coast of Scotland. Home to one of the first monasteries in Scotland, founded by St. Columba in CE 563, Iona is regarded as the cradle of Christianity in Scotland. In 2013 a new museum was created by Historic Scotland (an executive agency of the Scottish Government, with responsibility for historic monuments) to display a large collection of early Christian to late medieval carved stones that trace the turbulent story of the island and its peoples (Historic Scotland 2014). Although the stone collection bears little or no light-sensitive material the designers, Kevan Shaw Lighting Design, kept the light levels in the museum low. This low light level evokes a sense of dimly lit chapels and cloisters amongst the monastic surroundings. Further drama is created with the deliberate positioning of the light fittings

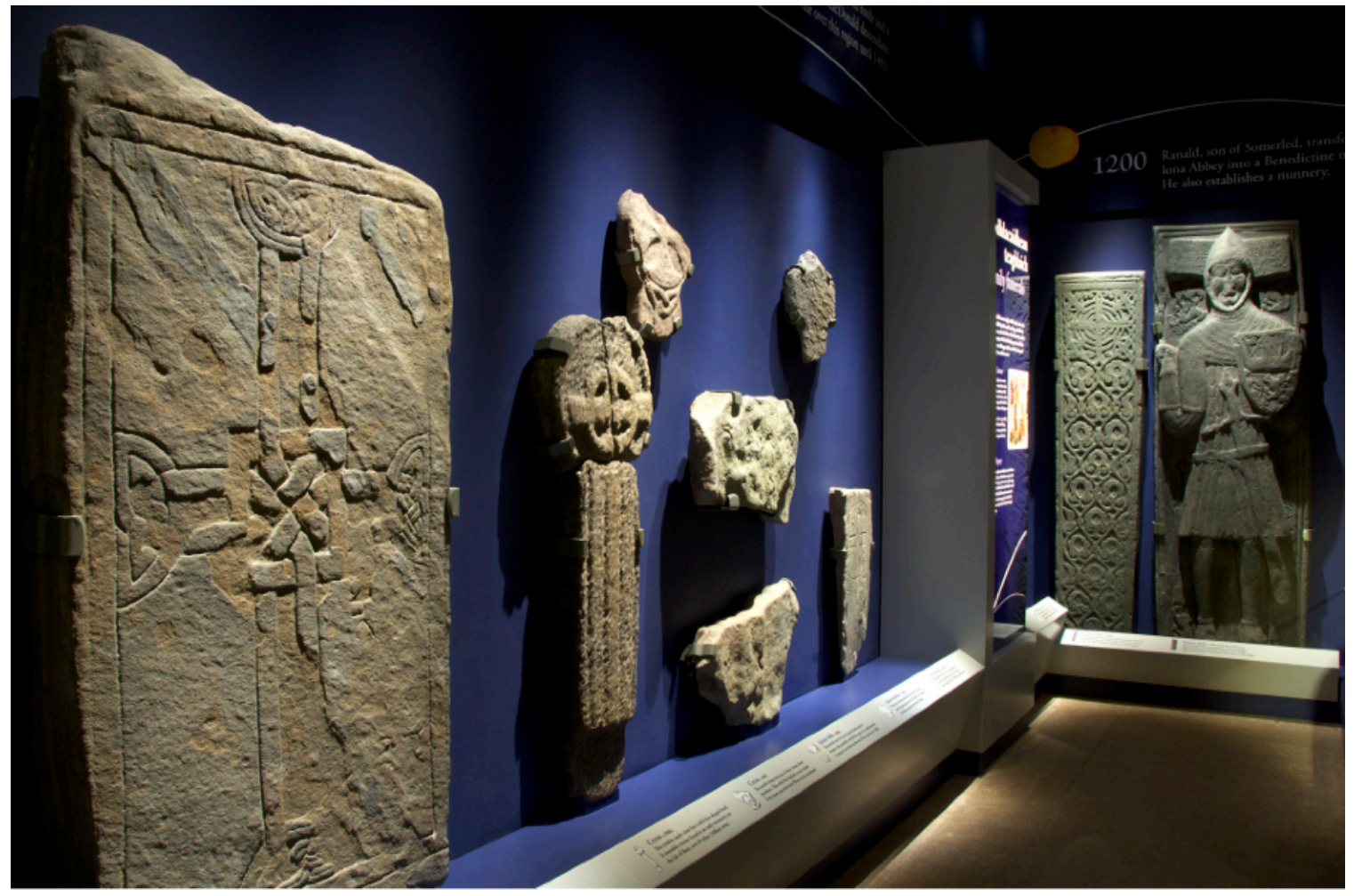

Figure 1: Iona Abbey Museum, Island of Iona, Scotland. Lighting design by Kevan Shaw Lighting Design. The use of high angle lighting is not simply a method of keeping the lighting out of sight and reach of the visitor, but is a deliberate choice that has allowed the designer to make the exhibits stand out from their surroundings and, most importantly, creates dramatic modulation of light and shade to clearly reveal the surface texture of relatively flat exhibits 
to produce shallow-angle illumination to the exhibits (see Kotoula this volume for raking light). As the light grazes the carved stones, it produces crisp shadows that reveal the texture of the stone (Cuttle 2013: 159) and highlights the intricate carving of Celtic crosses and late medieval warrior-chief grave slabs (Figure 1).

It is the deliberate and controlled use of shadow that renders these decorations so clearly and visually intelligible. By using single light sources on most objects, the shadows remain crisp and well delineated, with no multiple and overlapping shadows that could confuse the visual interpretation of the decoration. Although the three-dimensional form of the texture and carving is clearly inherent in the stones themselves, it is the skilful use of light that allows us to fully appreciate these aspects of the exhibits (also see Cuttle 2013: 157). We can demonstrate the truth of this through the experimental use of
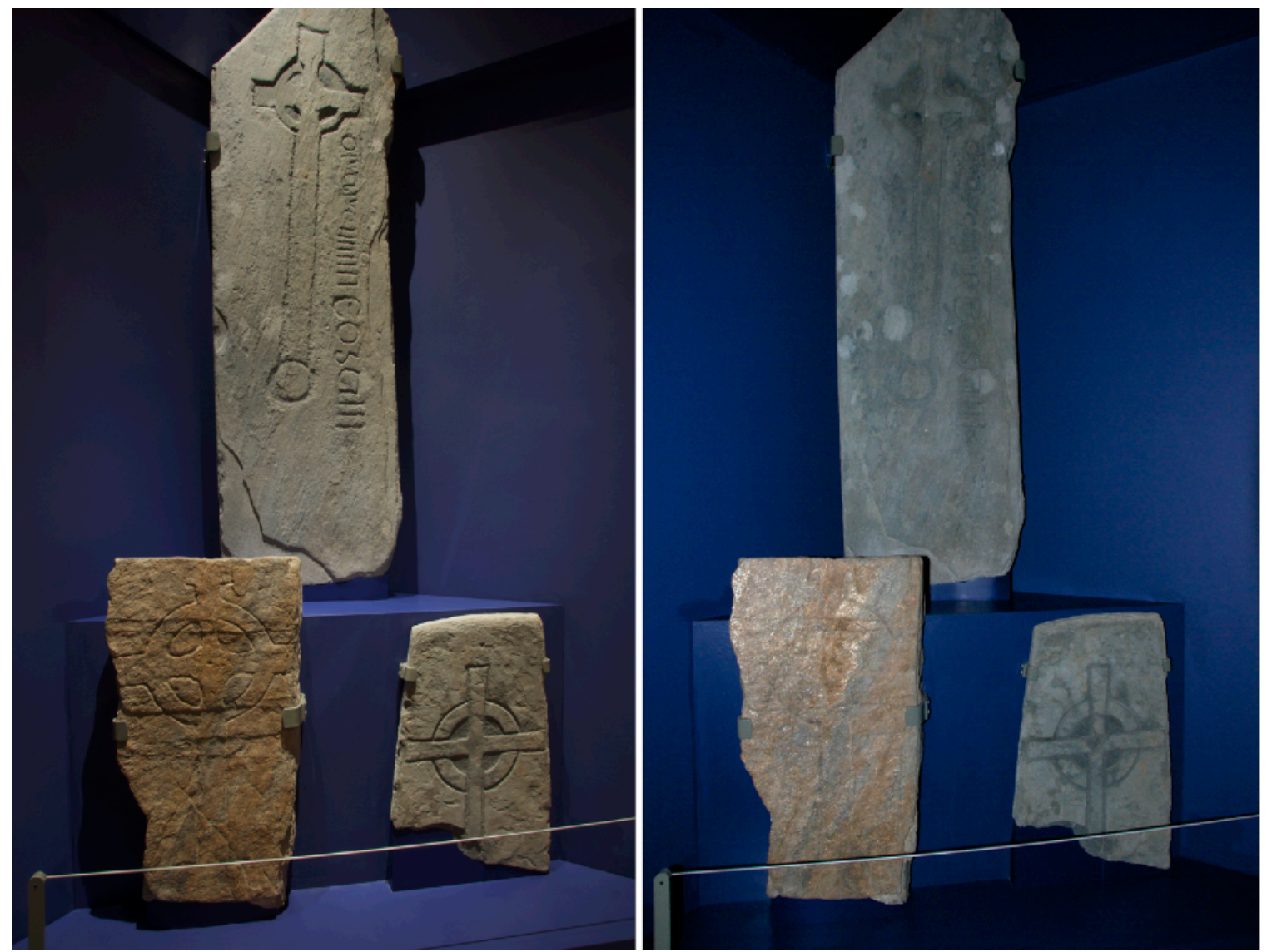

Figure 2: Iona Abbey Museum, Island of Iona, Scotland. Left image: original exhibit lighting design by Kevan Shaw Lighting Design. Designed with care and attention, the high angle lighting reveals the detailed incisions in the flat stone slabs used to create characteristic Early Christian crosses. Right image: the same objects, illuminated with a single light source positioned next to the camera demonstrates how easily the visual effect can be destroyed with bad lighting choices. 
an unsympathetic lighting direction to illuminate the same exhibits (Figure 2). As vivid and clear as the carvings may be when seen under the real exhibit lighting at Iona Abbey Museum (Figure 2a), the fragility of this visual information is clearly seen when the angle of lighting is changed. By adding a bright front light onto the display (Figure 2b), the carvings appear to have been erased from the stones. The nature of the stones themselves is also altered by this lighting direction. The tall stone at the rear of the display loses its surface texture and grain, and a distribution of circular stains or lichen marks on the stone becomes very obvious. In the lower left of the image, the colour appearance of the stone is completely altered, since the front light strongly reflects from mica schist or quartz within the stone to give it a glassy sheen. This light may reveal something different about the rock itself, but this particular exhibition is about the archaeology and not the geology of the stones. At the same time, the three carved stones seem to have been flattened, losing all three-dimensionality and the subtle depth cueing that is inherent in the properly designed exhibit lighting. Although this was a deliberately extreme example, the tendency to visually flatten objects is common where high levels of ambient light, such as diffused day-lit spaces or galleries predominantly lit with nondirectional fluorescent lighting, are present. Many of the stones on display at Iona Cathedral are carved into three-dimensional shapes or deep relief, making easier the task of using the lighting to render the three-dimensional form. However, the detail of some exhibits is not easy to illuminate.

\section{A sense of depth}

Maeshowe, a Neolithic chambered cairn in the Heart of Neolithic Orkney World Heritage Site, is a very fine example of slab-built tomb architecture of the period. It also has possibly the world's largest collection of runic inscriptions, carved as graffiti by twelfthcentury Viking visitors who were probably hunting for treasure in the tomb. Many of the exposed stone slabs inside the tomb are adorned with runic inscriptions and drawings possibly carved with the point of a knife (Foster 2006). The stone used to build the tomb is relatively soft but the carvings have survived. The faint inscriptions were perhaps not 
always so shallow; and even though they were largely protected from exposure to the weather, time has still softened the edges and made the lines less crisp. The challenge is to use light to help to reveal these fading stories.

A visit to Maeshowe means joining a small group led by a knowledgeable guide. On entering the tomb, ambient, diffused, and non-directional lighting comes from uplights illuminating the modern whitewashed roof. This provides a good overall level of

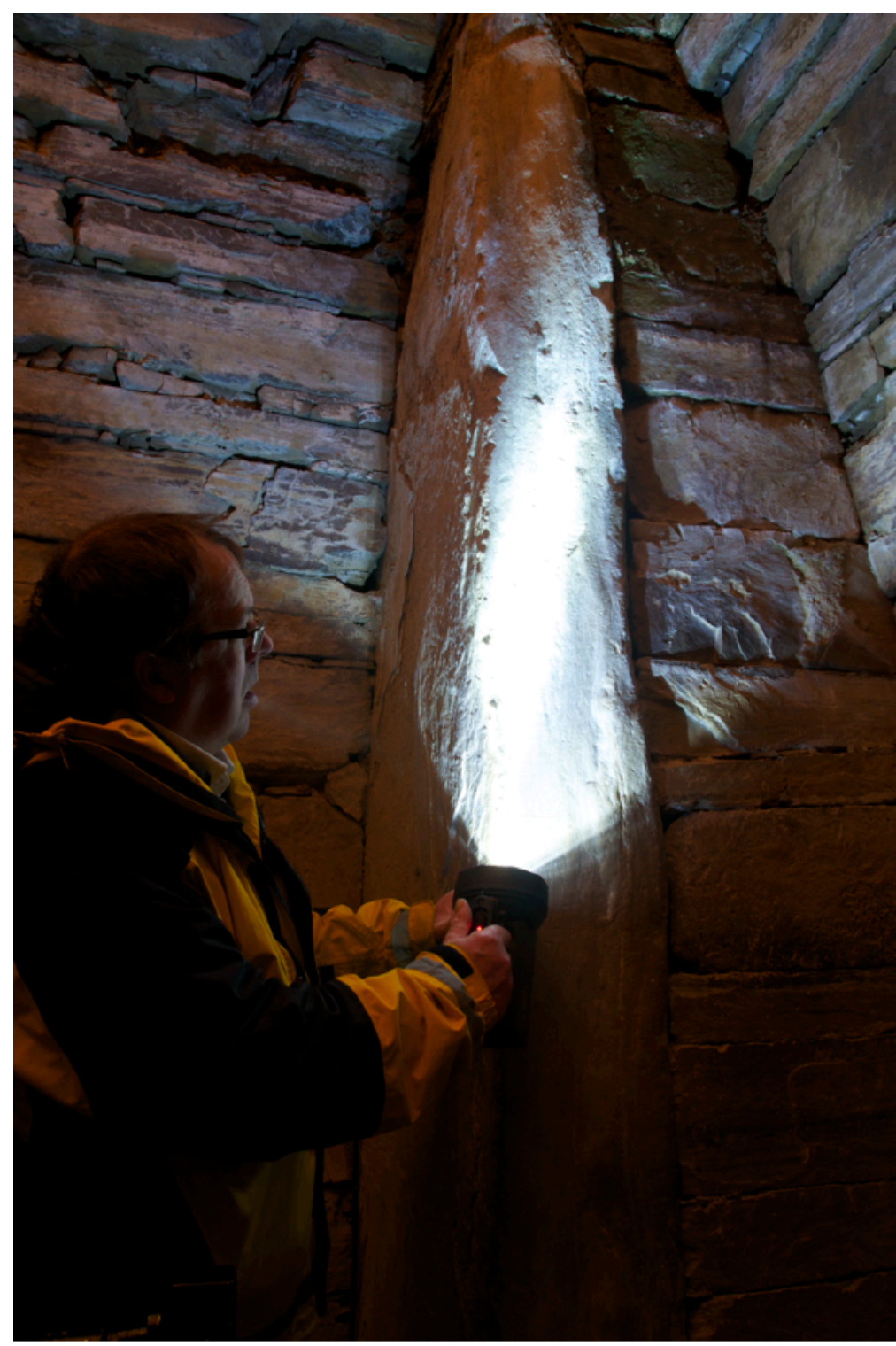

Figure 3: Maeshowe Neolithic Chambered Cairn, Orkney World Heritage Site. Tour guides use hand-held torches to direct the visitors attention to various features of the tomb and, with directional lighting, they can reveal faint runic graffiti, scribed on the walls of the tomb. light suitable for describing the construction of the Neolithic structure. At this stage, although surrounded by runic inscriptions, this light renders the inscriptions practically invisible to the visitors. To tell the story of the Viking incursions into the tomb, the guide dims the ambient light and uses a torch to 'point' to where there are inscriptions. He will then use the torch to graze light across the stones (Figure $3)$, creating shadows in the shallow carvings to allow the carvings to become visible.

The fact that the stones are far from smooth, along with the shallowness of the 
inscriptions, means that precise positioning of the light source is critical. Experiments carried out by the author on site (Figure 4) demonstrate how the direction of light affects the visibility of one of the tomb's most famous inscriptions, the Maeshowe Dragon. When the light falls too obliquely onto the stone (Figure 4a), the carving is spot-lit, but barely visible. If the lighting angle is too shallow (Figure $4 b$ ), the contours of the rock cast deep shadows that conceal the carving. It is only with shallow angle light from below, at around $15-30^{\circ}$ above a plane parallel to the slab, that the dragon appears with its foreleg raised and head turned back over the right shoulder to look at the Crusader's sword that protrudes from its back (Figure 4c). Although the importance of raking light in display has been appreciated for a considerable time (see Kotoula this volume), the very precise angles required to reveal inscriptions like the Maeshowe Dragon make it difficult to either give consistent guidance on how to achieve the best effect, or even to be able to reliably design a lighting installation without on-site testing by trial and error.

For many museum exhibits, the potential for light-induced fading means that we are only likely to ever see them in low-light conditions. By comparison, the runic inscriptions in Maeshowe are carved into inert stone surfaces and contain no fugitive
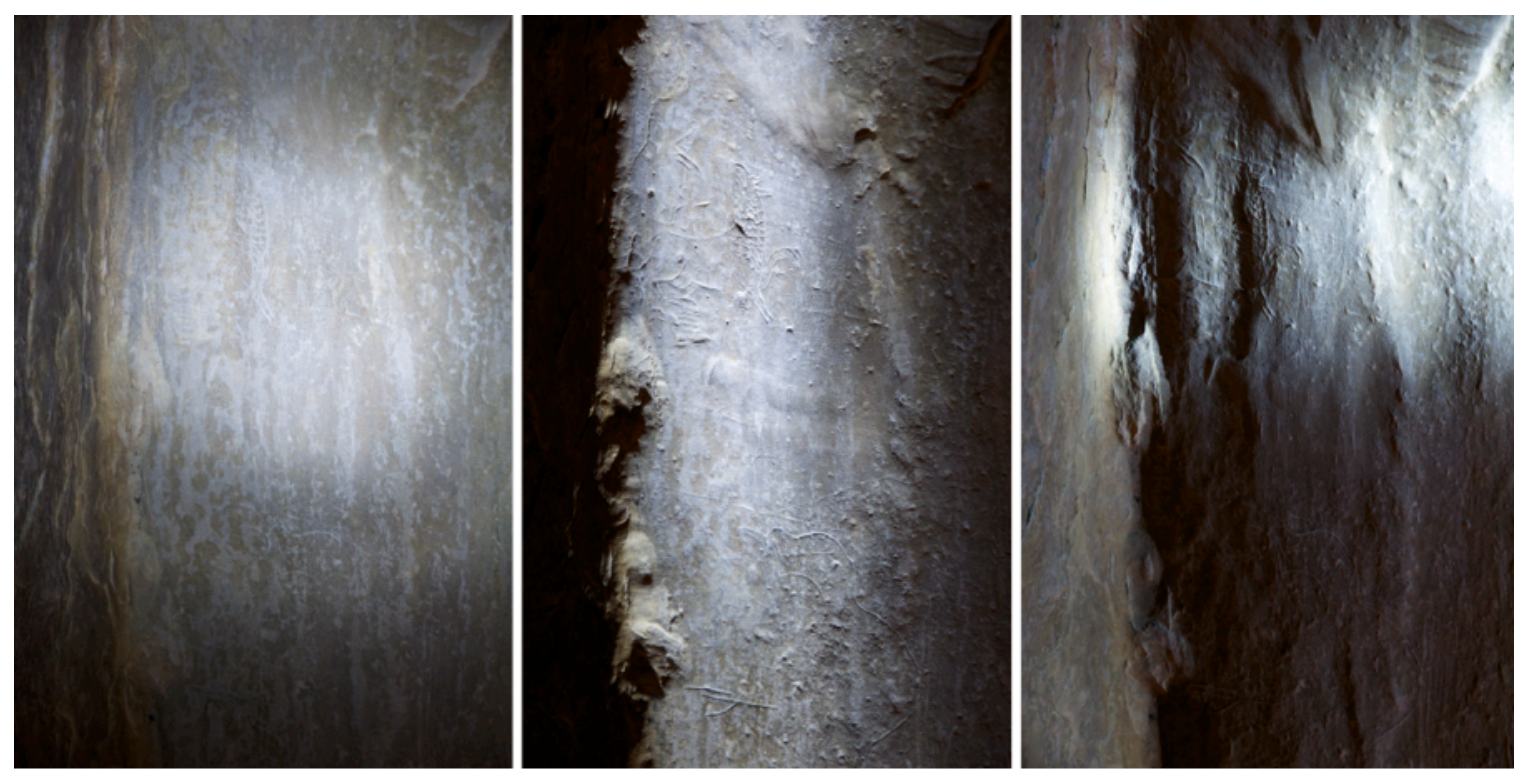

Figure 4: Maeshowe Dragon, Maeshowe Neolithic Chambered Cairn, Orkney World Heritage Site. Believed to have been carved by 12th century Viking Crusaders, the dragon (just above centre left of the middle image) is made up of very shallow scratched lines that are only visible when the angle of lighting is just right. 
pigments. Therefore, visible light has no significant adverse effect. Nevertheless, it is clear from these experiments that it is not always the quantity of light that defines how much visual detail can be extracted from an exhibit. The precise angle and direction of illumination is far more important than the quantity of light when trying to reveal shallow inscriptions.

It may have been hoped that these experiments with lighting direction would identify a better way to illuminate these carvings, but the results point to the great difficulty involved in designing effective lighting for this kind of exhibits. It is almost impossible to accurately predict in advance exactly how well the light will render the object without testing it with the real objects. Even with highly detailed 3D models built from sub-millimetre laser scans, the reflective or diffuse nature of each part of the exhibit's surface and its surroundings cannot be modelled in a way that accurately represents the visual experience of seeing the light on the object yourself. A lighting designer would therefore rely on extensive testing with the real exhibits and/or a large amount of flexibility on site to be able to move lights into the optimum positions. For Maeshowe, the hand-held torch is certainly the most cost-effective way to illuminate the inscriptions, but it may also be the most visually effective method, as it permits the guide to subtly alter the illumination to respond to the visual abilities and deficiencies of different visitors.

However, even with torches, things can be made better. The guides at Maeshowe have recently been supplied with Light Emitting Diode (LED) torches to replace the previous tungsten halogen versions. The new torches are brighter, more focused, and lower-power. However, a feature of these torches has been overlooked. Whereas the old torches featured a single low-voltage lamp in a highly polished reflector, the new torches feature multiple LED dies, each with its own focusing lens. The result is that the torch beam is effectively made up of several overlapping beams of lower power. Multiple light sources means multiple shadows, and even though the individual LEDs are mounted close together, they are still spread over an area that is larger than many of the carved features they are illuminating. The result is a diminution of the shadow effect because 
each LED casts its own shadow whilst filling in the shadows from other LEDs. The multi-lamp LED torches have reduced the energy usage for the display, but they have also reduced the visual effectiveness. Whether the exhibits are in situ or in a museum, changes in lighting technology to reduce energy need to be very carefully considered to ensure that less energy does not result in a loss of visibility for the visitors.

\section{Phototropism}

It is not just the direction of light that can negatively affect our ability to read a visual scene; ambient light, reflections, and glare can all degrade the visual experience in museum environments. Much like many flowering plants, humans are phototropic, i.e. turning towards bright lights (Taylor and Socov 1974). This is not a conscious affectation: as brighter light improves our visual acuity, exploring the brightly lit areas first is an evolutionary shortcut that aids the rapid assessment of the relative safety or otherwise of our surroundings (Rijswijk et al. 2012). This response is hardwired into our subconscious and is difficult to override. Therefore, our gaze tends to be naturally drawn to the brightest object in our field of view. This can be problematic when the objects in our eyeline are not bright enough. As a result, low-light museum displays are very susceptible to visual noise created by poorly designed lighting systems. In any sensory system, where there is too little difference between the signal and any random noise in the system, the signal will not be perceivable (for a description of more generalized principles behind signal to noise ratios in design, see Lidwell et al. 2010: 224-225).

Skara Brae, the Neolithic village site on the edge of the Heart of Neolithic Orkney World Heritage Site in northern Scotland, has a small museum in the visitor centre that displays finds from the site alongside replicas and recreations of everyday objects used by the Neolithic inhabitants. As is common in museums worldwide, most objects are mounted within display cases to protect the contents. The laminated glass walls of the case that separates the visitor from the exhibits are nominally transparent, but in reality, complete transparency does not exist. Typically, around 10-15 per cent of the visible light reflected from the surface of a displayed object will be lost in the glass surrounding it, 
dimming the image that reaches our eyes. For example, the technical specification for Pilkington 12mm Optiwhite glass (Pilkington 2015), which is commonly used for museum display cases, quotes a direct transmittance factor for visible light of $88 \%$ and a reflectance factor of 8 per cent (the remaining 4 per cent is lost through absorption and scattering within the glass). Most of the light loss caused by the glass is light that is reflected back by the highly polished surface of the glazing. A reflectance factor of 8 per cent is not very high, but the low light conditions of museum displays mean that even this seemingly small amount of reflection can significantly affect vision.

The light reflected from the outer surface of a glass display case can produce veiling reflections - clearly delineated reflections that appear overlaid on top of the objects inside the case (Boyce and Raynham 2009: 39). Figure 5 presents the display case in the Skara Brae visitor centre, which contains Neolithic pottery fragments and modern re-creations of pots with interpretation text printed directly onto the black painted backboard of the case. The intended effect is to make the range of dull ochre exhibits stand out clearly against the black background by maximizing the contrast range (Hughes 2010: 114). However, reflections in the glass case have created a confusing mix of real and reflected images. The large orange rectangle in the centre of the image is the reflection of an overly bright backlit graphic panel on the other side of the room. The dark shape that cuts through this orange reflection is the silhouette of another museum visitor. To the right of the orange rectangle, a vertical line of white dots is the reflection of internal fibre-optic lighting in another display case to the right of the camera position. All of these extraneous light sources appear layered on top of the objects inside the case, reducing the contrast between exhibits and their surroundings and making the text especially difficult to read.

In the top centre of the display case illustrated in Figure 5, there is a very clear reflection of three high-level spotlights used to light other exhibits in the museum. The reflection of these light sources introduces another type of visual disruption-discomfort glare (Boyce and Raynham 2009: 39). Although the reflection of the light sources does not obscure objects inside the display case, the intensity is distracting, and the effect is 
exacerbated by the very

high contrast between the

light source and the dark

background. In low light

conditions, we must be

aware of how the visual

system is likely to try to

adapt, and work carefully

to avoid any unintended

reduction in visual acuity

caused by direct and

reflected glare.

The human visual

system constantly adapts to

different lighting

conditions by adjusting the

amount of light that

reaches the retina (Boyce

and Raynham 2009: 24;

Gregory 1997: 92).

Normally, this provides

optimal viewing conditions

in a wide range of light

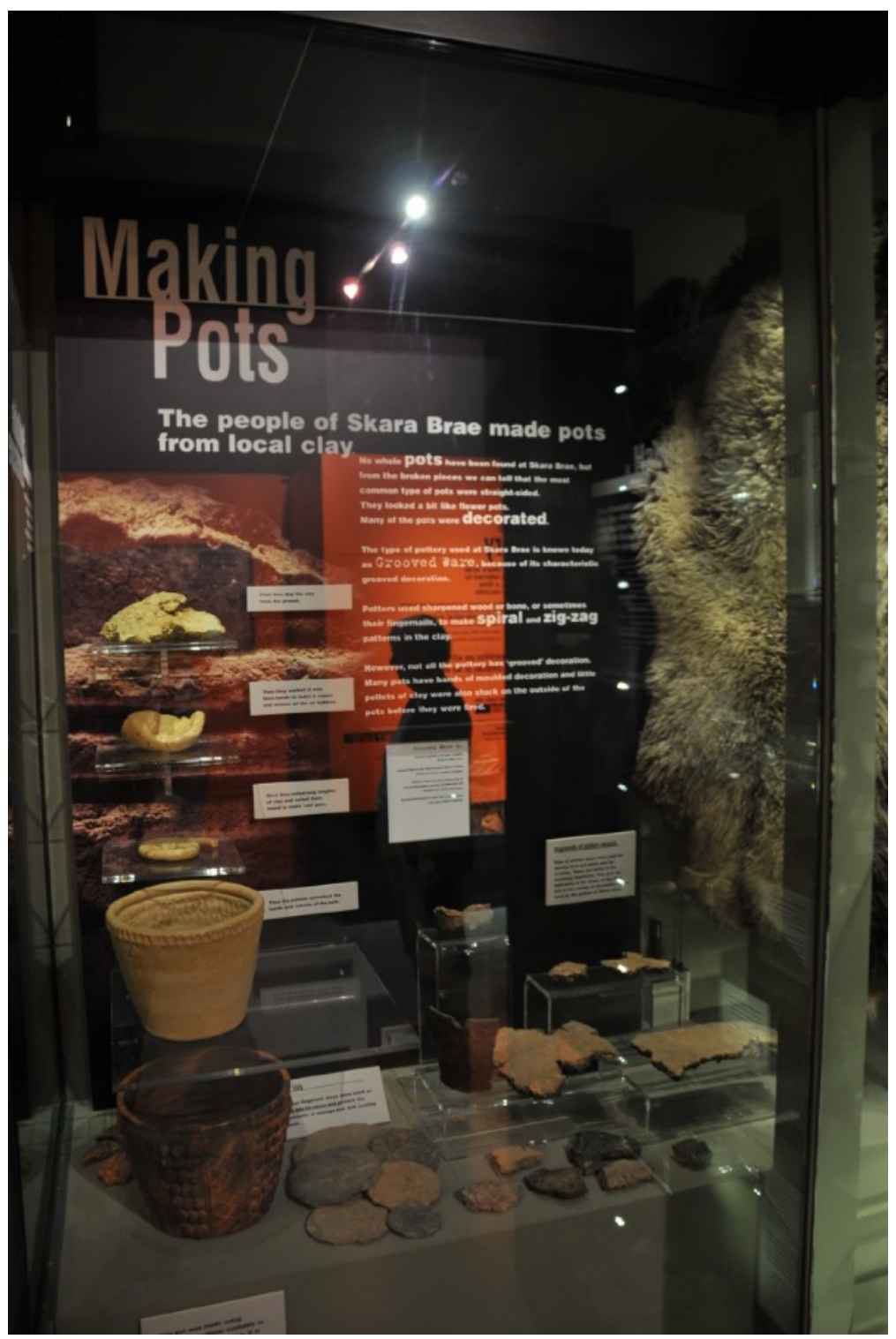

Figure 5: Skara Brae Visitor Centre Museum, Orkney, Scotland. Reflections in display cases can severely impede the visibility of dimly lit exhibits. This example shows how a veil of reflected light can overpower the case contents, leaving the display practically unintelligible.

levels (Gregory 1997: 85).

However, when presented with a very bright light source in the field of view, such as bright spotlights reflected in glass, the visual system will adapt to the brighter source by closing the iris to reduce the amount of light entering the eye (Mueller and Rudolph 1970: 54). This prevents glare that causes a disruption of vision, but the net effect is a general dimming of the whole scene. This dimming reduces the visibility of the low-light 
exhibits even further, and makes details in the dark areas even harder to discern. Where the visual system cannot reconcile very high contrast levels, such as a spotlight seen against a black ceiling, disability glare can be created. Disability glare is caused when light from excessively bright sources scatters inside the eye and interferes with the light received from the darker ambient view (Boyce and Raynham 2009: 38). Although eyes do not capture light in the same way as a camera, the image of the display case at Skara Brae (see Figure 5) shows the camera's equivalent to disability glare. At the top of the image, three spotlights are seen reflected in the glass case. The visible flare around these points of light is caused by reflection and refraction inside the camera lens, and this smearing of the light obscures any detail that may lie in that area of the image. A very similar effect happens within the human eye when we look at bright points of light against a dark background. In the context of a low-light museum display, glare can be visually disastrous and it requires a lot of careful spatial planning and three-dimensional design thinking to avoid serious problems (see Innes 2012: 98, 100; also Cuttle 2013: 20, 57 , and further examples of how to deal with common glare problems in museums).

\section{Subconscious visual effects}

In The User Illusion, a fascinating tour through the connection between the senses and consciousness, Danish science writer Tor Norretranders $(1999,173)$ states that 'the ingenuity of consciousness consists not of the information that it contains but the information that it does not contain'. Our sensory systems receive and process far more data than we are ever consciously aware of. For our sense of taste, the sensory system has a bandwidth of around 1,000 bits per second, but consciously, we only process around 1 bit per second — a 1,000:1 difference. All our senses work in a similar way, but vision has the greatest disparity between the quantity of data gathered and data consciously acted upon. The bandwidth of our eyes - the total amount of sensory data that they can collect

- equates to around 10 million bits per second. And yet we are only consciously aware of around 40 bits per second (Zimmermann 1989). 
Vision accounts for a very large amount of the processing power of the human brain, but our mind would be overwhelmed if we had to consciously assess all the information received by the eyes; hence the data is heavily pre-filtered. This process not only serves to reduce the load on conscious thought processes by excluding nonimportant data; it is also an important evolutionary imperative. There is normally at least a 0.5 -second delay between receiving a sensory stimulus and our conscious reaction to that stimulus (Norretranders 1999). The low-level pre-filtering of the incoming sensory data means that we are often reacting to danger long before we become consciously aware of the threat (Carretié et al. 2005; Norretranders 1999).

Pre-filtering of visual data takes many forms, but one example is that when movement is detected in the peripheral vision, the eyes tend to swivel toward the movement to bring this potential threat into the central and sharpest area of vision (Gregory 1997: 98). We also have a tendency to turn our eyes towards areas of bright light (although dazzlingly bright highlights will have the opposite effect); this happens as a reflex and outwits our conscious control. Unconsciously turning towards bright light sources can affect our adaption to low light levels. In order to maintain dark-adapted night vision, vehicle drivers need to train themselves not to be drawn into looking into the headlights of oncoming traffic. However, as Michel (1995: 164) has noted, the phototropic effect is evident even in 6-day-old babies, who will instinctively turn towards the light of a day-lit window if carried past it.

Poorly designed lighting installations are often beset by the phototropic response, with our gaze being easily distracted by unwanted reflections and excessive brightness in all the wrong places. However, a well-designed lighting scheme can actively use the same effects to alter and control the visual hierarchy of a museum display, adding weight to the visual stimulus exactly where it is needed. If a spot-lit object is rendered brighter than its surroundings, we can persuade the visual system that this object is worth looking at, whereas a dark area may not be worth exploring. This is all part of creating a visual hierarchy in the lighting that aids interpretation and general wayfinding (Innes 2012: 74, 92). It may seem obvious that spotlighting an object will make it stand out and give it a 
sense of importance, but this can be very difficult to achieve in the very restricted range of illumination available in low light galleries. Nevertheless, a well-designed lighting scheme will make good use of the psychology and physiology of sight to reinforce the narratives we wish to convey with the museum display (Pinto et al. 2006).

\section{Metrics of lighting quality}

Exhibition lighting in museums and galleries strives to render the true nature of the surface of the exhibits. This would include using light sources that provide the most accurate rendering of colour and tone. White light sources have a number of metrics that help to describe the visual effect of seeing objects under that illumination (Innes 2013). Colour temperature (more correctly known as Correlated Colour Temperature or CCT) is measured in degrees Kelvin, and is used to describe the subtle tint of white between warm and cool. Exhibition lighting would typically have a CCT between $2,700 \mathrm{~K}$ and $3,500 \mathrm{~K}$ (Scuello et al. 2004); this would be described as warm white. Below 2,700K, is the very warm amber tint of candle light or firelight. Around 4,000K would be described as neutral white (although it would appear quite cool if surrounded by warmer light sources), and higher CCTs would be described as cool white; very high CCTs can appear comparatively blue when used in interior spaces. The range of colour temperatures used in electric lighting for museum displays is comparatively limited, with most institutions using sources in a range between $2,700 \mathrm{~K}$ and $4,000 \mathrm{~K}$. On the other hand, daylight can have a very wide range of colour temperatures. A study in Granada in Spain (HernándezAndrés et al. 2001) collected 2,600 measurements of daylight spectra that covered a range of $3,758 \mathrm{~K}$ to $34,573 \mathrm{~K}$. The modal figure, being around $5,600 \mathrm{~K}$, is considerably higher than the typical colour temperature range for electric light.

Another dimension of white light is a measurement of how accurately colours appear when illuminated by the light source. One long-standing metric for this is the Colour Rendering Index (CRI, established in 1965 by the Commission Internationale de l'Éclairage (CIE) and updated in 1974 and 1995) (CIE 1995). This metric compares a defined set of sample colour chips illuminated under the test source and a reference 
source of the same CCT. The visual similarity of the two sets of colour chips are given a numerical grade and the results are averaged to give a rendering score, with 100 being a perfect result. A CRI score of greater than 90 would normally be seen as ideal for museum lighting (Cuttle 2013: 25), as it suggests that exhibit colours would not be distorted by the light source. However, the CRI has very significant limitations, and LED sources can score poorly despite producing a high-quality visual experience for the viewer (Rea 2010). Despite its known limitations, CRI remains in use mainly because of the lack of a widely accepted and more reliable alternative. It should be noted that a very high CRI score might not mean that all colours will be perfectly rendered. As Boyce and Raynham (2009: 199) note, 'the CIE general colour rendering index is a single number describing a complex perception.' Other metrics have been proposed; most recently the Illuminating Engineering Society of North America have published their IES TM-30-15 colour rendition method (IES 2015), which aims to address many of the limitations of the CRI. However, even if it becomes widely adopted, it may still not perfectly reflect colour vision at museum light levels. Therefore, white light sources should always be tested, especially where exhibits contain saturated colours, to ensure that the lit effect is what is expected.

\section{Virtual restoration}

Good-quality white light can be the ideal medium to accurately reveal the surface colour and material qualities of exhibits. But sometimes the current surface appearance of the object does not represent what the object would have originally looked like. Despite the almost ubiquitous use of white light in exhibition lighting, there is sometimes scope for a different approach (Pinto et al. 2008).

A research project that was begun in 2012 by Edinburgh Napier University for Historic Scotland has explored the virtual restoration of stone artefacts using projected light. Using digital projection techniques, it is possible to selectively illuminate parts of the exhibit and use intensity, colour, and projected pattern for interpretive purposes. Figure 6 shows before-and-after images of a life-size medieval (c.14-15th c.) funeral 
effigy of a bishop from Elgin Cathedral. Although the extant effigy retains a high level of detail in the carving, the surface appears to be raw sandstone. Closer examination, for example of the upper arm, reveals very small areas of paint. In contradiction to most casual viewers' expectation of a monochromatic past, this object was once highly decorated, with naturalistic colours for the bishop's robes and gilding to his mitre.

Using evidence gathered from tiny paint fragments, conservators have been able to reproduce a palette of colours that would have decorated the original carving. This polychrome finish is almost completely lost now, and even where some small fragments still remain, chemical changes in the pigments and later overpainting has significantly reduced the vibrancy of colour. Therefore, using white light to illuminate the effigy will give the viewer little impression of what the original, and intended visual effect would have been.

The advent of reasonably bright LCD/DLP video projectors that use LED and laser light sources means that the lamp life of these projectors is now up to ten times that of other projector types. The lower power and extended lamp life (greater than five years in typical exhibition use) means that LED/laser projectors can be used in museum environments without the problems of changing very expensive lamps every few months. Whereas image projectors normally rely on projecting onto a flat screen surface, projection mapping overlays a projected image onto a 3D surface to create an irregular shaped display screen. Computer manipulation of the image can correct distortions that are created by projecting onto planes that are not perpendicular to the projector. This technology shift has allowed this research project to explore how projection mapping can be used to virtually restore the polychrome finish to artefacts that have lost their surface decoration over the centuries. 

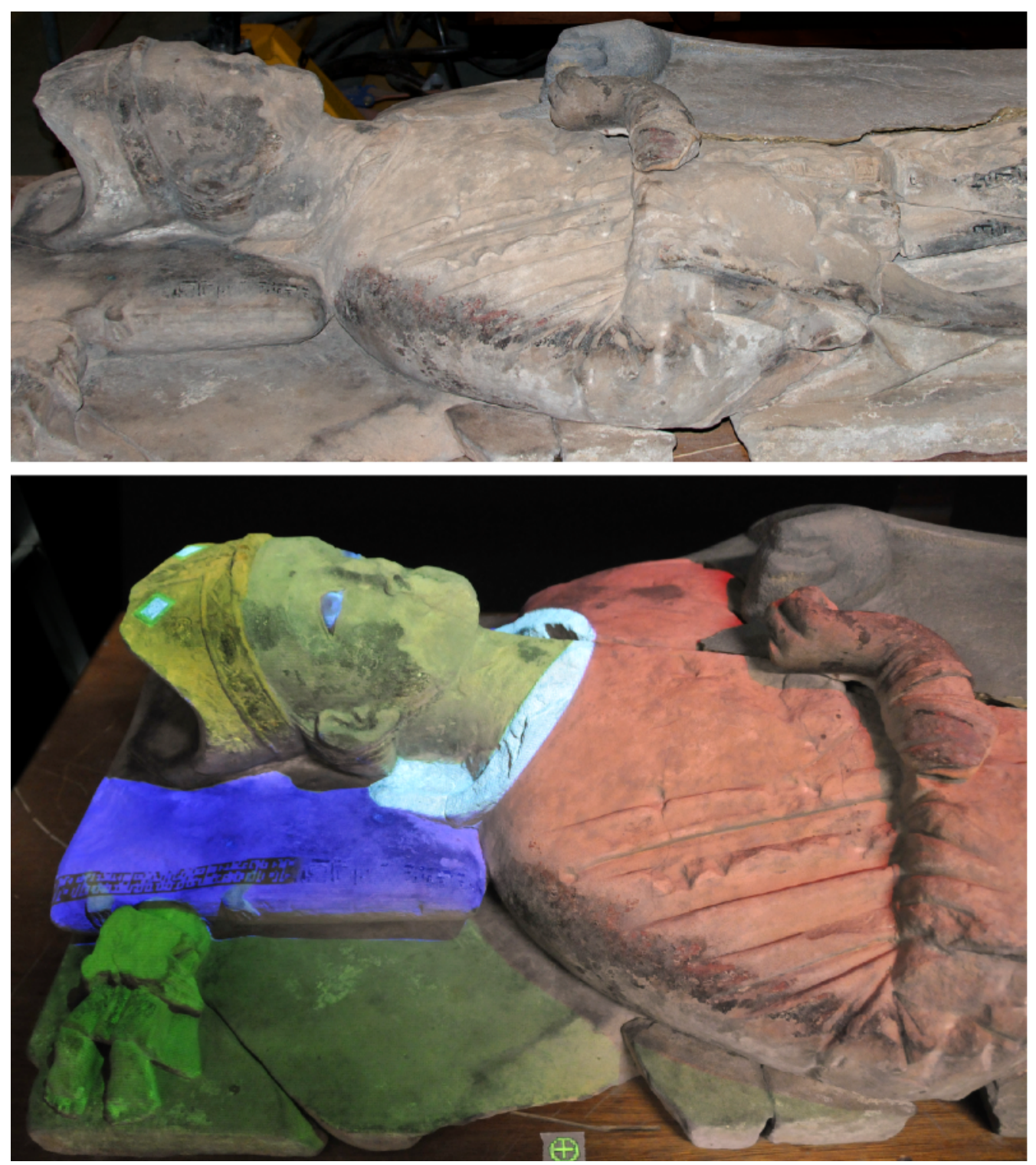

Figure 6: Bishop's Effigy from Elgin Cathedral. These before and after images were taken during a mock-up to test the potential of digital projection as a means of virtually restoring the effect of the original polychrome finish on damaged artefacts. Most colours in the projection test are based on analysis of surviving paint, some colours (such as the eyes or the green base) are speculative or diagrammatic to enhance contrast. 


\section{Conclusion}

The world of museum lighting is at the beginning of a new era. After decades of refinement of white light sources to produce faithful renderings of object colour, the opportunities afforded by solid state lighting sources (LEDs) and digital projection means that the future may not all be white light. Projected colour and pattern is likely to have an increasingly important place in the interpretation of some objects and environments. At the same time, the variable tuning of LED light intensity and colour over the surface of an object will become easier and more affordable (Pinto et al. 2008).

The future is likely to include many more customized LED light sources (Vaicekauskas et al. 2012), with spectral outputs tuned to suit the specific exhibits on display (Ritter et al. 2013). Examples such as Iannone's (2013) lighting designs for paintings by Titian and other Italian Renaissance masters, and the 2014 relighting by Osram of the Michelangelo's frescos in the Sistine Chapel (BBC 2014), are currently uncommon, but will quickly become the norm in high quality museum lighting.

Nevertheless, high-technology light sources or digital projection are not a panacea for all the difficulties of conservation lighting. For museum visitors, the visual connection to the museum object is vital. As discussed in this chapter, much of the interpretive story can be revealed by good lighting, or concealed by bad lighting. Well-considered lighting positions can reveal textures or shallow carvings whilst minimizing glare and other visual distractions. It is therefore clear that the illumination of museum displays still requires a high degree of skill and dedication to fully elucidate the detailed stories that are bound to the precious objects. Although digital technologies do not replace the need for these fundamental skills, they open up new avenues of lighting exploration (such as the use of projection or customised white-light sources) that can be individually tuned to suit the objects on display and the audience viewing them. If handled sensitively, this will not only improve the visual experience for the viewer, but could also provide new interpretation opportunities. Perhaps the most important advance could be to achieve much better conservation outcomes to help preserve fragile exhibits for the enjoyment and education of future generations. 


\section{References}

BBC. 2014. Vatican Sistine Chapel gets new lighting and AC system. Available at: http:// www.bbc.co.uk/news/world-europe-29825898

Bomford, D. 1995. The history of colour in art. In Colour: Art and Science, ed. T. Lamb and J. Bourriau. Cambridge: Cambridge University Press

Boyce, P., and P. Raynham. 2009. The SLL Lighting Handbook. London: Chartered Institution of Building Services Engineers.

Cain, J. 2005. Teaching through objects: a user's perspective. Natural Sciences Collections Association News 7: 2-7

Carretié, L., J. Hinojosa, F. Mercado, and M. Tapia. 2005. Cortical response to subjectively unconscious danger. NeuroImage 24: 615-623

Casati, R. 2004. Methodological issues in the study of the depiction of cast shadows: a case study in the relationships between art and cognition. Journal of Aesthetics and Art Criticism 62(2): 163-174

CIE [Commission Internationale de l'Éclairage]. 1995. Method of measuring and specifying colour rendering properties of light sources. Available at: http:// www.cie.co.at/publ/abst/13-3-95.html

CIE. 2004. Control of Damage to Museum Objects by Optical Radiation. Vienna: CIE.

Classen, C. 2007. Museum manners: the sensory life of the early museum. Journal of Social History 40(4): 895-914

Cuttle, C. 2008. Lighting by Design, 2nd edn. London: Routledge.

Cuttle, C. 2013. Light for Art's Sake: Lighting for Artworks and Museum Displays, 2nd edn. New York: Routledge.

Dean, D. 1994. Museum Exhibition Theory and Practice. London: Routledge

Finney, L. 2006. Basic conservation and environmental monitoring. Association of Independent Museums Focus Paper. Available online at: http://www.aimmuseums.co.uk/downloads/ffe7f644-dd7d-11e1-bdfc-001999b209eb.pdf (accessed Mar. 2015).

Forbes, R. J. 1971. Studies in Ancient Technology. Leiden: Brill 
Foster, S. 2006. Maeshowe and the Heart of Neolithic Orkney. Edinburgh: Historic Scotland

Gregory, R. L. 1997. Eye and Brain: The Psychology of Seeing, 5th edn. Oxford: Oxford University Press

Hernández-Andrés, J. et al. 2001. Color and spectral analysis of daylight in southern Europe. Journal of the Optical Society of America A: Optics, Image Science, and Vision 18(6): 1325-1335. Available at: http://www.ncbi.nlm.nih.gov/pubmed/ 11393625

Historic Scotland. 2014. About Iona Museum redisplay project. Available at: http:// www.ionahistory.org.uk/museum-redisplay-project (accessed Mar. 2015).

Hughes, P. 2010. Exhibition Design. London: Laurence King Iannone, F. 2013. Lighting for the Titian exhibition in Rome: the impact of neuroaesthetics on the design process. In Professional Lighting Design Convention, Rome, Italy, 30th October-2nd November 2013. Gütersloh: VIA.

[IES] Illuminating Engineering Society. 2015. TM-30-15: The IES Method for Evaluating Light Source Color Rendition. New York: IES.

Innes, M. 2012. Lighting for Interior Design. London: Laurence King Innes, M. 2013. Is there a right white for gallery lighting? In Conference Proceedings: Professional Lighting Design Convention 4th Global Lighting Design Conference, ed. A. Ritter. Gütersloh: VIA.

Kleffner, D. A., and V. S. Ramachandran. 1992. On the perception of shape from shading. Perception and Psychophysics 52(1): 18-36

Lidwell, W., K. Holden, and J. Butler. 2010. Universal Principles of Design. Beverley, Mass.: Rockport.

Maxwell, J. C. 1865. A dynamical theory of the electromagnetic field. Philosophical Transactions of the Royal Society of London 155: 459-512. Available at: http:// www.jstor.org/stable/108892 
McKie, R. 2012. Neolithic discovery: why Orkney is the centre of ancient Britain. Observer, 6 Oct. Available online at: http://www.theguardian.com/science/2012/ oct/06/orkney-temple-centre-ancient-britain (accessed Aug. 2015).

Michel, L. 1995. Light: The Shape of Space Designing with Space and Light. New York: John Wiley .

Mueller, C., and M. Rudolph. 1970. Light and Vision. Amsterdam: Time-Life International.

Museums Galleries Scotland 2014. What is Collections Care? Edinburgh: Museums Galleries Scotland. Available online at: http:// www.museumsgalleriesscotland.org.uk/research-and-resources/resources/ publications/publication/122/what-is-collections-care (accessed Mar. 2015).

National Library of Australia 2014. Policy on the illumination of collection material on display. Available online at: http://www.nla.gov.au/policy-and-planning/ illumination-of-collection-material (accessed June 2014).

Norretranders, T. 1999. The User Illusion: Cutting Consciousness Down to Size. London: Penguin Books.

Pilkington. 2015. Pilkington Optiwhite performance data. Available online at: https:// www.pilkington.com/en-gb/uk/products/product-categories/special-applications/ pilkington-optiwhite\#performancedata (accessed Nov. 2015).

Pinto, P., J. Linhares, J. Carvalhal, and S. Nascimento. 2006. Psychophysical estimation of the best illumination for appreciation of Renaissance paintings. Visual Neuroscience 23(3-4): 669-674

Pinto, P., J. Linhares, and S. Nascimento. 2008. Illuminant spectrum maximizing the number of perceived colors in art paintings. In Proceedings of Conference on Colour in Graphics, Imaging, and Vision, CGIV 2008, 505-7. Available at: http:// www.ingentaconnect.com/content/ist/cgiv/2008/00002008/00000001/art00108

Pye, E. (ed.). 2008. The Power of Touch: Handling Objects in Museum and Heritage Context. Walnut Creek, Calif.: Left Coast Press 
Rea, M. S. 2010. A practical and predictive two-metric system for characterizing the color rendering properties of light sources used for architectural applications. In Proc. SPIE 7652, International Optical Design Conference 2010, ed. J. Bentley,

A. Gupta, and R. N. Youngworth. Available at: http:// proceedings.spiedigitallibrary.org/proceeding.aspx articleid $=759267$

Rijswijk, L. V., A. Haans, and Y. de Kort. 2012. Intelligent street lighting and perceptions of personal safety. In Proceedings of EXPERIENCING LIGHT 2012: International Conference on the Effects of Light on Wellbeing, 1-4. Available at: http://purl.tue.nl/688591309207942.pdf

Ritter, A., G. Poldi, and G. Castoldi. 2013. The revolution has begun. Professional Lighting Design 85: 44-50

Saunders, D., and J. Kirby. 1994. Light induced colour changes in red and yellow lake pigments. National Gallery Technical Bulletin 15: 79-97.

Scuello, M., et al. 2004. Museum lighting: why are some illuminants preferred? Journal of the Optical Society of America A: Optics, Image Science, and Vision 21(2): 306-311.

Shaw, K. 2000. Museum lighting: three case studies. Professional Lighting 4(1). Available at: http://www.kevan-shaw.com/ksld_upload/pdf/ 2000_Professional_Lighting_January2000_Vol4\%20No1.pdf

Spark, R. 2010. Object handling in the archaeology classroom: strategies for success. University Museums and Collections Journal 3: 191-195. Available at: http://edoc.huberlin.de/umacj/2010/sparks-191/PDF/sparks.pdf

Taylor, L. H., and E. W. Socov. 1974. The movement of people towards lights. Journal of the Illuminating Engineering Society (Apr.): 237-241.

Thomson, G. 1957. Visible and ultraviolet radiation. Museums Journal 57(2): 27-32.

Thomson, G. 1963. The influence of light on museum objects. In International Institute for Conservation of Historic and Artistic Works, Recent Advances in Conservation: Contributions to the IIC Rome Conference 1961. London: Butterworth. 
Thomson, G. 1986. The Museum Environment, 2nd edn. Oxford: ButterworthHeinemann.

Trylski, T. (ed.). 2015. Lighting Guide 8: Lighting for Museums and Art Galleries. London: Society for Light and Lighting.

Vaicekauskas, R., et al. 2012. Color rendition engine. Optics Express 20(5): 593-598.

Zelanski, P., and M. Fisher. 1999. Colour, 3rd edn. London: Herbert Press.

Zimmermann, M. 1989. The nervous system in the context of information theory. In Human Physiology, ed. F. Schmidt and G. Thews. Berlin: Springer 